\title{
Second Generation Asian-Indian Reactions To Asian-Indian And American Magazine Advertisements
}

Durriya H. Z. Khairullah, (Email: durzk@sbu.edu), Saint Bonaventure University Zahid Y. Khairullah, (Email: syk@sbu.edu), Saint Bonaventure University

\begin{abstract}
This paper is an extension of a previous study which addressed cultural perceptions of first generation Asian-Indians. The current study includes second generation Asian-Indians in the U.S. (The United States of America) and compares their reactions to the first generation subjects regarding Indian magazine advertisements versus American magazine advertisements of the same product class. The results indicate that cultural perceptions of the second generation Asian-Indian are similar to cultural perceptions of first generation Asian-Indians in the earlier study. In general, both generations appear to prefer Indian advertisements more than the corresponding American advertisements. This offers opportunities for U.S. marketers to continue to develop culturally attuned advertising strategies to effectively reach the growing and affluent Asian-Indians in the U.S.
\end{abstract}

\section{INTRODUCTION}

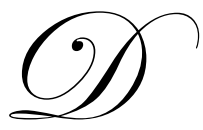

uring the last decade, several U.S. marketers have developed culturally sensitive advertising campaigns to reach the Asian-Indian consumers residing in the U.S. These marketers include long-distance telephone companies, airlines, insurance, Indian restaurants, and matchmaking/dating services (Krishna, 1997;

Mogelonsky, 1995). The researchers have contended that an ethnic segmentation strategy has been successful in communicating effectively with Asian-Indian consumers and that the Asian-Indians tend to patronize those marketers who are sensitive to developing culturally attuned advertisements to reach them. The same articles also point out that the Asian-Indian community has grown rapidly in the last decade and among all ethnic groups in the U.S., the Asian-Indians have the highest per-capita income and therefore present a great opportunity for marketers to cater to them. In 1980, there were only 387,000 Asian-Indians in the U.S., however by 1997, this figure had more than tripled to 1,215,000 (Hathaway, 2001). By the latter date, the Asian-Indian community constituted the third-largest Asian American population in the country, surpassed by Chinese and Filipino Americans. A larger percentage (58\%) of the Asian-Indian immigrants have at least a bachelor's degree (compared to $21.5 \%$ of whites) and hold managerial and professional positions more than any other group in the country, with especially high representation among the more remunerative professions. Due to their concentration in the medical, scientific, and computer fields, the per capita income of Asian-Indians exceeds that of every other group in the country (including whites) except Japanese Americans (Hathaway, 2001). Several studies have reported that most of the Asian-Indian immigrants in the U.S. sampled in their studies are married, highly educated, wellto-do individuals coming from urban areas of India (Dasgupta, 1988; Khairullah and Khairullah, 1999; Mehta and Belk, 1991; Sodowsky and Carey, 1988). Although language, regional, and religious differences may divide Asian-Indians immigrants in the U.S. they share a large number of common underlying cultural values. They all place a great value on education, financial security, and family (Krishna, 1997; Mogolensky, 1995).

The aim of this exploratory research is to examine the cultural perceptions of the second generation AsianIndians in the U.S. for Indian magazine advertisements versus American magazine advertisements of the same product class and compare them with the first generation Asian-Indians of an earlier study by Khairullah and Khairullah, 2003. The study also reports the preferences of second generation respondents for Indian versus the American advertisements and compares them with those of first generation Asian-Indians of the same earlier study. In essence the impetus of the 
present study is based on one of the future research propositions of studying the perceptions of second generation Asian Indians and comparing their perceptions to the first generation Asian-Indians sampled in Khairullah and Khairullah's 2003 study. The results of such studies could enable marketers to reinforce their continuous efforts of developing an effective advertising strategy aimed at the growing affluent Asian-Indian market in the U.S.

\section{METHODOLOGY}

\section{Sample}

The sample for the present study consisted of thirty-nine second generation Asian-Indians. Data was collected through a semi-structured open-ended questionnaire given to the respondents in their homes. The respondents took approximately thirty minutes to complete the research. The written responses of each of the respondents were pooled and common themes emerging from these responses are reported in this paper.

The second generation Asian-Indian sampled consisted of both males and females born and raised in the U.S. or came to the U.S. with their parents as very young children. They were between the ages of 18-32, either they were in high school, working toward their undergraduate degree or some already had undergraduate or graduate degrees. Out of thirtynine respondents only five were married. Those respondents who were students were dependent on their parents, while those with undergraduate and graduate degrees were employed and independent. A majority of (90\%)f the respondents were Hindus while the rest were Muslims. All of the respondents were residing in the metropolitan cities of the U.S. Most of their parents who settled in the U.S. came from the large cities in India.

\section{Advertisement Stimuli}

To test cultural perceptions and preferences of second generation Asian-Indians for Indian versus American magazine advertisements, Indian magazine advertisements of coffee, cooking oil, man's suit, refrigerator, shampoo, and tea and corresponding American magazine advertisements of the same products were shown to the participants. These products were selected because they are common consumer products and advertisements for these products frequently appear in Indian and American magazines. All of the advertisements were in color and approximately of the same size. The same magazine advertisements of the above mentioned products had been shown to the first generation Asian-Indians in the earlier study.

\section{Procedure}

The questionnaire given to the second generation Asian-Indian respondents was in English and the advertisements shown to the respondents were in English. Since India was under British rule for nearly 200 hundred years, English is still one of the official languages used in India to conduct official business and commercial transactions (CIA, The World Factbook-India, 2004). Each one of the second generation respondents was instructed to see the six pairs of Indian and corresponding American advertisements of the same products one after the other. Upon seeing each pair, they had to list in their own words the differences they perceived in the Indian versus the American advertisements for the same product on the questionnaire provided to them. On the same questionnaire they were asked to write down which one of the two advertisements (Indian or American) they preferred more than the other.

\section{DISCUSSION}

A summary of the cultural perceptions of the second generation Asian-Indians for the Indian magazine advertisements versus the American magazine advertisements for the same product class appear in Exhibit 1. The observations reported in Exhibit 1 indicate that the second generation Asian-Indians sampled in this study often made the obvious remark that Indian advertisements had Asian-Indian models. They also said that they could see clearly the cultural differences manifested in the Indian versus the American advertisements in terms of models' dress, appearance, background, and the activities that they were performing in the advertisements. For example, the Indian models in the advertisements were shown as wearing a traditional Indian dress - sari, Indian jewelry while the 
American female models were shown in western clothing - short dress, sweater, and jeans. The couple in the Indian suit advertisements was watching a traditional religious dance of India while in the American suit advertisement the couple was shown romancing. The female models in the Indian refrigerator, shampoo, and tea advertisements were seen as traditional conservative housewives while in the corresponding American advertisements female models were seen as career-oriented and confident individuals. These remarks are similar to the remarks made by the first generation Asian-Indians sampled in the earlier Khairullah and Khairullah, 2003 study regarding the cultural differences depicted in the Indian and the American magazine advertisements in terms of appearance of the models, their dress, background, and the activities that they were performing in the advertisements. Based on the results of the past and present study we conclude that not only the first generation Asian-Indians but also the second generation Asian-Indians have retained their home country's cultural values. The plausible explanations of the findings perhaps lie in understanding the notion of culture and in the findings of past studies that have examined the Asian-Indian culture.

Culture is defined as the "sum total of learned beliefs, values and customs that serve to direct the consumer behavior of members of a particular society" (Schiffman and Kanuk, 2004 p. 408). The impact of culture is natural and automatic and its influence on behavior is usually taken for granted. Culture satisfies the needs of the people within a society. It offers order, direction, and guidance to satisfy physiological, personal, and social needs. Hence, our food preferences, the way we dress, the verbal and non-verbal communications that we engage in, various ritualized experiences and behaviors that we go through, and the product and services that we buy are reflective of our cultural values. Furthermore, culture is frequently considered as a group customs that link together the member of a society such that its values, experiences, and customs are shared by the members of that particular society. Culture is dynamic and it gradually and continually changes to meet the needs of society. Culture is learned as part of social experience. Children learn from their parents and environment a set of beliefs, values, and customs that constitute culture. A number of social institutions such as family, educational institutions, houses of worship, and mass media play a major role in communicating the cultural values and make sharing of culture a reality in the societies. The mass media transmit cultural values both through editorial content and through advertising to a large number of audiences at the same time and at an economically feasible price. Consumers are exposed daily to advertising. Although the function of advertising is to influence demand for specific products and services, nevertheless in a cultural context the role of advertising is to reinforce conventional cultural values and help communicate new tastes, habits, and customs (Schiffman and Kanuk, 2004).

Since advertising acts as an agent of social change in society, it is necessary for marketers to design advertising campaigns in a way that reflects the cultural values of their target audience (Schiffman and Kanuk, 2004). Studies on the first generation Asian-Indians have found that Asian-Indians sampled were nostalgic about their saris and jewelry and they did wear them on special occasions (e.g., Dasgupta, 1989; Mehta and Belk, 1991). Indian cultural identity in terms of her arts and crafts such as household shrine, ancestors' photographs, heirloom, furniture, embroidery, carpentry, wood and metal works, and religious objects such as deities of Indian gods and godesses were found in the homes of the Indian immigrants in the U.S. by several researchers (e.g., Gandhi 1970; Kaul 1977; Mehta and Belk 1991). Earlier studies have also reported that Asian-Indian immigrants in the U.S. were mindful of their social and religious duties (e.g., Gandhi 1970; Mehta and Belk 1991; Sodowsky and Carey 1987).

The concept of building relationships with family and community members is very important to Asian-Indians. These relationships exist between a father and son, a husband and wife, between siblings and friends has been stated by Krishna (1997). Sodowsky and Carey (1987) in their study concluded that the upbringing and personality of AsianIndians are partly shaped by the influence of extended family. Through infancy, childhood, adolescence, and adulthood they are expected to depend on their parents, grandparents, older siblings, and aunts and uncles. A married son with his family continues to live with parents. The Indian-family system also provides a sense of security where family members think that they are responsible for helping each other whenever need arises. 


\section{EXHIBIT 1}

\section{Frequent Responses For Cultural Differences Perceived By Second-Generation Asian-Indians For Indian Versus American Advertisements}

\section{I-A Indian Coffee Advertisement}

* Well-to-do, sophisticated Indians models dressed in expensive traditional Indian clothes are socializing against a luxurious Indian décor.

* Coveys that affluent Indians drink coffee when they are socializing and entertaining.

\section{I-B American Coffee Advertisement}

* Background is simple, tells a story reflecting memories, the female model is wearing a white bridal dress.

* Coveys that coffee is considered as a simple every day drink.

\section{II-A Indian Cooking Oil Advertisement}

* The female Indian models are shown wearing Indian dress.

* Indian extended family are shown appreciating several dishes of cooked Indian food.

\section{II-B American Cooking Oil Advertisement}

* A single young attractive Caucasian woman conscious of her health is shown promoting the cooking oil.

\section{III-A Indian Man's Suit Advertisement}

* The female model is shown wearing the Indian dress and jewelry.

* A traditional looking Indian couple watching an Indian dance and the emphasis is on spirituality.

\section{III-B American Man's Suit Advertisement}

*A couple is shown in a provocative pose, emphasis is on sex, liberalism, modernity, and seductiveness.

\section{IV-A Indian Refrigerator Advertisement}

* The Indian female is wearing Indian dress.

* The Indian female model looks conservative, traditional, shy, and friendly.

\section{IV-B American Refrigerator Advertisement}

* The female model appears a career-oriented who looks confident and independent.

* The female model is wearing western clothes.

\section{V-A Indian Shampoo Advertisement}

* The Indian female model appears married, conservative, shy, homely, sweet, modest and her make-up is simple.

\section{V-B American Shampoo Advertisement}

* The female model looks glamorous, seductive, aggressive and is scantily dressed.

\section{VI-A Indian Tea Advertisement}

* The Indian male and female models are shown in Indian dress.

* The models appear conservative, traditional, family-oriented type with natural smiles.

\section{VI-B American Tea Advertisement}

* The female model is wearing a western dress, lots of make-up, looks adventurous with a fake smile. 
Several studies have found that compared to Americans, Asian-Indians in the U.S. have differences in term of their social and cultural values. Dasgupta (1989) in her study found that Asian-Indian immigrants see Americans as extroverts, practical, honest, technology oriented, self-confident, self-sufficient, hard working, assertive, lonely, and selfcentered and Asian-Indians consider themselves as introverts, emotional, knowledgeable but less practical, confident, individualist, and very much oriented towards the family and society. The results of the present study support the characteristics of culture of being natural, shared, learnt, satisfying needs and wants, dynamic, and handed down from generation-to-generation. The second generation Asian-Indians sampled in our study appears to have learned the cultural values from their parents and other social institutions to which they are exposed.

It is interesting to note that although the first generation and the second generation Asian-Indian respondents had similar perceptions of cultural differences depicted in the Indian versus the American magazine advertisements on several fronts, there were also some differences. The second generation respondents used stronger language in describing the extent of sex portrayed in the American man's suit advertisement and the shampoo advertisement (e.g. using words like: seductive, liberalism, etc.) whereas the first generation respondents were more subdued in describing the presence of sex for the same advertisements (e.g. romancing). The second generation respondents did not specifically mention the Indian artifacts by their Indian names as did the first generation respondents (e.g, "thali," "diva," etc.).

The overall preferences of the second generation Asian-Indians for Indian versus American magazine advertisements are tabulated in Exhibit 2. The result in this exhibit show that the majority of the second generation AsianIndians, like the first generation Asian-Indians of the earlier study, preferred Indian advertisements more than the American advertisements with the one exception, for man's suit advertisement, where the preference of second-generation Asian-Indian was more for the American advertisement. However, a statistically significant preference for the AsianIndian advertisements was found only in the advertisements of the following three products: cooking oil, shampoo, and tea. The difference in the preferences for the coffee, man's suit, and the refrigerator advertisements were not significant.

The preference for the American man's suit advertisement over the corresponding Indian man's suit advertisement may perhaps be due to the fact that most men (not women) in urban areas of India wear western clothes (Tyabji, 1985). Mehta and Belk (1991) in their study found that several Indian women in the U.S. did not wear saris on a routine basis, they did make it a point to wear them along with their wedding jewelry on special occasions such as parties, holidays, and evenings out. Men did not cite Indian clothing as favorite possessions and did not wear Indian clothes very often. Moreover, in most of the Indian advertisements the male models were wearing western clothes.

\section{EXHIBIT 2}

Overall Preferences Of Second Generation Asian-Indian Respondents For Indian Versus American Print Advertisements

\begin{tabular}{|c|c|c|c|c|}
\hline & $\begin{array}{c}\text { Product } \\
\text { Advertised }\end{array}$ & $\begin{array}{c}\text { Asian-Indian } \\
\text { Advertisement }\end{array}$ & $\begin{array}{c}\text { American } \\
\text { Advertisement }\end{array}$ & $\begin{array}{c}\text { Chi Square } \\
\text { Significance }\end{array}$ \\
\hline 1. & Coffee & $54 \%$ & $46 \%$ & 0.6310 \\
\hline 2. & Cooking Oil $*$ & $62 \%$ & $23 \%$ & 0.0008 \\
\hline 3. & Man's Suit & $39 \%$ & $61 \%$ & 0.1495 \\
\hline 4. & Refrigerator & $54 \%$ & $46 \%$ & 0.6310 \\
\hline 5. & Shampoo & $69 \%$ & $31 \%$ & 0.0065 \\
\hline 6. & Tea & $77 \%$ & $23 \%$ & 0.0008 \\
\hline
\end{tabular}

Note: Cooking Oil * : 16\% of the subjects had the following responses: "Not Sure" or "Like Both Advertisements"

In the cases of the coffee advertisement and the refrigerator advertisements, it appears that the second generation respondents' preference for the Indian advertisement as well as for the American advertisement were rather close, whereas the first generation (in the earlier study) clearly preferred the Indian advertisement to the American advertisement. Although there is no clear explanation for this finding, we feel that perhaps the copy of the Indian refrigeration advertisement may have been perceived by the second generation Asian-Indian respondents as emphasizing the role of 
women to be overly submissive in this modern age. Although the second generation Asian-Indian respondents' overwhelmingly said that the female model in the Indian refrigerator looked like a traditional conservative housewife, maybe they do not see themselves growing up in the U.S. in this role. In January 2003 issue of the Family Circle magazine an advertisement by Kodak showed a first generation Asian-Indian woman dressed in an Indian dress (sari) and wearing Indian jewelry lovingly looking at her daughter (second generation) who is dressed in western clothes (t-shirt and pants) and has a 'mod' look with lots of make-up and trendy western jewelry. In the case of the coffee advertisements, the models and the décor in the Indian advertisement were mixed, western as well as Indian, and so the ethnic differences between the American and the Indian advertisements were not clear. This may have resulted in the more or less equal preferences for the two coffee advertisements. The preferences between the two advertisements for coffee and between the two advertisements for refrigerator, shown in Exhibit 2, are not statistically significant.

\section{CONCLUSION}

While interpreting the results of this study, we must keep in mind that the sample size of the second generation Asian-Indians was small, which may limit the generalizability of the findings. All of the Indian and the American print magazine advertisements used in this study were selected in such a way that they reflected the cultural differences between them. Hence, the results of this study must be considered as exploratory. Nevertheless, the findings of this study have potential implications for marketers. Not only have the first generation Asian-Indians retained their cultural values but they have passed their cultural values on to their children. The children have learnt and can perceive the cultural differences depicted in the Indian versus American magazine advertisements. Moreover, Asian-Indian immigrants with their growing numbers and favorable socio-economic characteristics provide a lucrative market. Those marketers who take the initiative in developing culturally attuned advertisements to reach Asian-Indians should continue their efforts in doing so to retain the loyalty of Asian-Indians in patronizing their products. Other U.S. marketers could also make an effort in developing culturally sensitive advertising campaigns and thereby winning the loyalty of this affluent market. Furthermore, the Asian-Indians can be reached by several English language Indian print media that are available in the U.S. (e.g. India Abroad, India News, India Today, and Stardust).

The results of this study together with the earlier studies imply that not only the first generation Asian-Indian immigrants but also the second generation Asian-Indian respondents sampled in this study see themselves (through their cultural values, rituals, clothing, furnishings, religion, etc.) as a distinct group within the U.S., and are committed to retaining their home country's cultural values.

Some of the limitations of the present study can provide future research directions. A larger sample of second generation Asian-Indians should be considered. Indian versus American advertisements appearing in other media such as broadcast media could be studied. Advertisements of other products and product classes can be investigated.

\section{REFERENCES}

1. CIA - The World Factbook - India (2004). http:/www.odci.gov/cia/publications/factbook/geos/in.html.

2. Dasgupta, S. S. (1989). On the Trail of an Uncertain Dream: Indian Immigrant Experience in America. New York: AMS Press, Inc.

3. Gandhi, R. S. (1970). Conflict and Cohesion in an Indian Student Community. Human Organization, 29 (2, Summer), 95-102.

4. Hathaway, R. M. (2001). Unfinished Passage: India, Indian Americans, and the U.S. Congress. The Washington Quarterly. Center for Strategic and International Studies and the Massachusetts Institute of Technology, 24 (2), 21-34.

5. Kaul, M. L. (1983). Adaptation of Recently Arrived Professional Immigrants from India in Four Selected Communities of Ohio. Journal of Applied Social Behavior, 20, 100-108.

6. Khairullah, D. Z. and Z. Y. Khairullah (1999). Behavioral Acculturation and Demographic Characteristics of Asian-Indian Immigrants in the United States of America. International Journal of Sociology and Social Policy, $19(1 / 2), 57-80$.

7. Khairullah, D. Z. and Z. Y. Khairullah (2003). Use of Projective Techniques for Studying Reactions of Asian- 
Indians to Print Advertisements, in Proceedings of the 2003 International Applied Business Research Conference.

8. Krishna, B. M. (April 25, 1997). Culturally Sensitive Ad Campaign by NY Life. India Abroad, 26.

9. Mehta, R. and R. W. Belk. (1991). Artifacts, Identity, and Transition: Favorite Possessions of Indians and Indian Immigrants to the United States. Journal of Consumer Research, 17 (March), 398-411.

10. Mogelonsky, M. (August, 1995). Asian-Indian Americans. American Demographics, 33-39.

11. Schiffman, L. G. and L. L. Kanuk (2004). Consumer Behavior. Upper Saddle River, NJ: Prentice Hall.

12. Sodowsky, G. R. and J. C. Carey (1987). Asian Indian Immigrants in America: Factors Related to Adjustment. Journal of Multicultural Counseling and Development, 15(3), 129-141.

13. Sodowsky, G. R. and J. C. Carey (1988). Relationships between Acculturation-Related Demographic and Cultural Attitudes of an Asian-Indian immigrant Group. Journal on Multicultural Counseling and Development, $16,117-135$.

14. Tyabji, L. (1985). Handicrafts and Fabrics, in I. Samuel and B. Grewal, eds. India: Insight Guide. APA Productions (HK) Ltd: India, 293-297.

\section{NOTES}




\section{NOTES}

